\title{
Reporte de caso: Paciente con adenocarcinoma de próstata metastásico e infección por SARS-CoV-2 tratado con medicina biorreguladora
}

\author{
María Camila Londoño Murillo ${ }^{1}$
}

Corresponding Author: María Camila Londoño Murillo, camilamdintegrativa@gmail.com

${ }^{1}$ Universidad de Antioquia, Docente de cátedra, Especialista en Terapéuticas Alternativas y Farmacología Vegetal - Universidad Juan N Corpas | camilamdintegrativa@gmail.com

\begin{abstract}
Enfrentar la infección por SARS-CoV-2 ha sido uno de los mayores retos para el personal de salud a nivel mundial en el último año y han sido muchas las alternativas de tratamiento propuestas para el manejo de la infección; entre ellas, la homotoxicología ha sido perfilada como una de las terapias opcionales para tratar a los pacientes dentro del gremio de los profesionales de la salud que bien conocen sus potenciales mecanismos de acción y

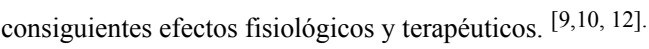

En este caso, veremos cómo un paciente con adenocarcinoma de próstata metastásico luego de iniciar quimioterapia y en franco deterioro de su calidad de vida y de su estado nutricional; adquiere la infección por SARS-CoV2 con consiguiente neumonía y múltiples factores de mal pronóstico, pero logra rápida recuperación sin secuelas al recibir un tratamiento con abordaje desde la biorregulación.
\end{abstract}

Keywords: case report, SARS-CoV-2, prostate cancer, bioregulatory medicine

\section{$\underline{\text { Introduction }}$}

En diciembre de 2019 comenzó a detectarse en Wuhan, capital de la provincia de Hubei en China; un brote de neumonía grave. El 7 de enero de 2020 se identificó el agente etiológico: el virus SARSCoV-2 (Severe Acute Respiratory Syndrome 2), causante de la enfermedad por el nuevo coronavirus, COVID 19. En menos de 3 meses, el 11 de marzo de 2020, la OMS (Organización Mundial de la Salud, declaró la pandemia y hasta el momento continuamos en la búsqueda de tratamientos y soluciones que permitan disminuir el riesgo de contagio, de enfermedad grave, secuelas y muertes. ${ }^{[6,8]}$

En Colombia, el registro de casos comenzó a llevarse a cabo del 6 de marzo de 2020, y hasta la fecha hay registrados 4'187.194 casos, con 105.326 muertes. A nivel mundial se registran 181 '282.922 casos confirmados con 3'926241 muertes. ${ }^{[2]}$

El agente se transmite por el contacto con gotas del sistema respiratorio superior de los infectados, y por otras vías de infección: orofecal, vertical, sexual y la presentación clínica de la enfermedad por COVID 19 puede abarcar desde síntomas leves (es la presentación más común) como tos, fiebre, escalofríos, diarrea; hasta neumonía grave, siendo la falla ventilatoria asociada a neumonía la principal causa de muerte $(85 \%)$ por infección del virus.

Si bien la enfermedad puede ocurrir a cualquier edad, los más afectados son varones de mediana edad, los adultos mayores y personas con condiciones especiales como tabaquismo, enfermedades pulmonares de base, hipertensión arterial, diabetes. Adicionalmente, se cuentan entre los factores de mal pronóstico para neumonía: linfopenia, elevación de LDH y de troponina I. ${ }^{[6,8]}$

Los pacientes con neoplasias malignas constituyen un grupo importante de riesgo, pues hasta el $41.3 \%$ de los casos pueden corresponder a adquisición intrahospitalaria y, teniendo en cuenta que estos pacientes requieren constantemente atención y monitoría en estas instituciones, es factible considerar el alto riesgo que corren sin mencionar el deterioro de su sistema inmunológico. El 
presente reporte expone el caso de un paciente que, ante todos los factores de mal pronóstico logra una evolución satisfactoria tanto en su enfermedad oncológica como en la neumonía por SARS-

CoV-2. ${ }^{[6,8]}$

El enfoque de la MBrS (Medicina Biorreguladora de Sistemas) implica, como punto de partida, identificar el estado de inflamación del paciente como resultado de la perturbación del terreno y en ocasiones es tal la gravedad del mismo, que se debe optar por un tratamiento supresivo o con la biorregulación como complemento. Sin embargo, algunos pacientes también se pueden beneficiar únicamente de la MBrS, obteniendo excelentes resultados. ${ }^{[4,10,12]}$

\section{Timeline}

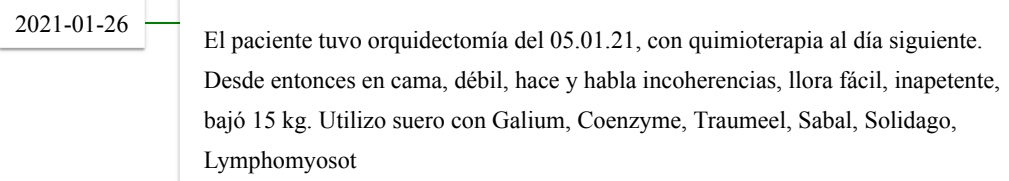

2021-01-28 — Paciente con franca mejoría, se levanta de la cama, mejor apetito, mejor ánimo. Aún se siente ansioso con sensación de angustia en la noche. Se realiza sueroterapia con coenzyme, ubichinon, traumeel, galium, sabal compositum.

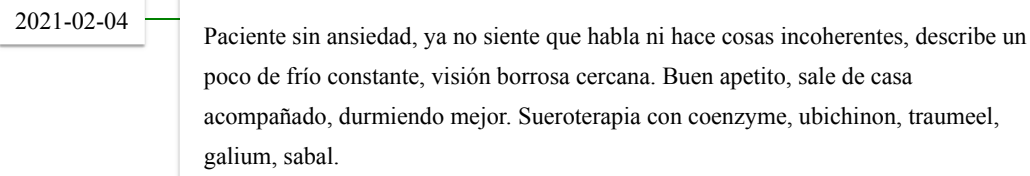
poco de frío constante, visión borrosa cercana. Buen apetito, sale de casa acompañado, durmiendo mejor. Sueroterapia con coenzyme, ubichinon, traumeel, galium, sabal.

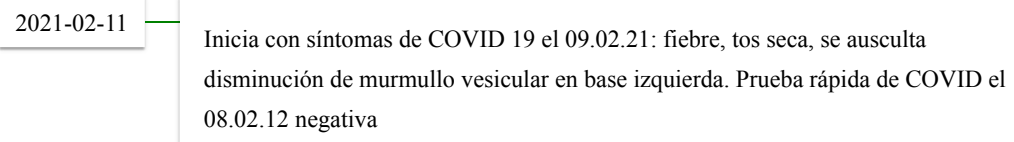
disminución de murmullo vesicular en base izquierda. Prueba rápida de COVID el 08.02.12 negativa


su sintomatología. Se realiza sueroterapia con Hepar, Sabal, traumeel, Ubichinon y Galium.

\section{1-02-18 - Paciente sin tos, sin disnea, mejoría de la fatiga. Se observa orofaringe eritematosa, auscultación cardiopulmonar sin alteraciones. En su EPS le realizan exámenes y a partir de ellos consideran inicio de amoxicilina/ácido clavulánico, paciente no acepta}

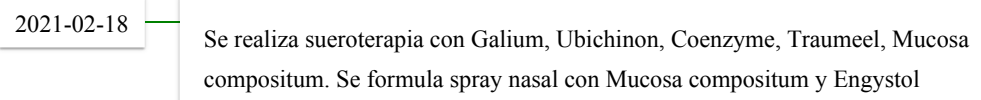
compositum. Se formula spray nasal con Mucosa compositum y Engystol

2021-02-19 - Rx de tórax revela atelectasia izquierda, infiltrados intersticiales reticulares de distribución bilateral, clasifica como RALE 4 (moderado), nódulos en pulmón derecho sin cambios respecto a estudio previo. Auscultación pulmonar sin alteraciones. 


\begin{tabular}{|l|l|l|l|l}
\hline 2021-02-25 & $\begin{array}{l}\text { Dados los resultados de paraclínicos y rx de tórax en su EPS deciden ordenar O2 por } \\
\text { cánula a } 1 \mathrm{~L} 2 \mathrm{~h} \text { en las noches, pero el paciente relata tos y disnea asociado a esto. De } \\
\text { manera particular, se decide suspender la terapia e iniciar sueroterapia. }\end{array}$ \\
\hline 2021-03-05 - & $\begin{array}{l}\text { Ya resolvió cuadro agudo de COVID 19 pero dice que persiste con dolor en tobillos, } \\
\text { cansancio en miembros inferiores y dolor abdominal, deposiciones diarreicas. Se } \\
\text { indica continuar sueroterapia semanal con el mismo esquema previo. }\end{array}$ \\
\hline 2021-03-20 & $\begin{array}{l}\text { Había resuelto la diarrea pero reapareció con rinorrea hialina, disfagia y estornudos. } \\
\text { Se formula sueroterapia con engystol, echinacea, traumeel, euphorbium y coenzyme. }\end{array}$ \\
\hline Suda durante la noche pero dice que amanece con total recuperación al día siguiente \\
\hline 2021-04-08
\end{tabular}

\section{$\underline{\text { Narrative }}$}

Paciente masculino de 51 años, publicista, con diagnóstico de adenocarcinoma de próstata con metástasis hepática en abril 2020, se le propuso orquiectomía con epidididectomía y quimioterapia paliativa, las cuales le fueron practicadas el 05.01 y el 06.01.21 respectivamente, cursando con hidronefrosis e insuficiencia renal aguda.

Se evalúa por primera vez al paciente el 26.01.21, luego de 20 días en los cuales había permanecido con astenia, adinamia, anorexia, ansiedad, depresión, terrores nocturnos y a veces hablando incoherencias, con gran pérdida de peso posterior a los procedimientos (peso previo $73 \mathrm{~kg}$, e el momento de la evaluación $59 \mathrm{~kg}$ ).

En esta primera valoración se encuentra al paciente en cama, con intolerancia al frío, PA 110/80 mmHg, FC 92 lpm, SaO2: 98\%, se palpa abdomen blando, doloroso a la palpación profunda en hipocondrio derecho y marco cólico izquierdo.

Se inició tratamiento con sueroterapia inicial bisemanal con Galium, Coenzyme, Traumeel, Sabal, Solidago, Lymphomyosot; estímulo en puntos de acupuntura 20 TM en tonificación, P6, 36 E; VO: Traumeel gotas 10 cada $8 \mathrm{~h}$, VIUSID 1 sobre cada $8 \mathrm{~h}$, Galium $30 \mathrm{CH} 10$ gotas cada $8 \mathrm{~h}$ y extracto de Divi divi + Anamú. 
Durante la segunda semana ya se evidencia importante mejoría: el paciente se levantó de cama, mejoró su esfera mental, apetito y estado general.

Se dio continuidad al tratamiento semanal en casa y al mes de haber iniciado éste presenta cuadro de tos seca, fiebre, disnea y escalofríos, por lo cual se le practicó prueba antigénica para SARS-CoV-2, la cual es reportada como negativa y se decide practicar PCR, la cual resultó POSITIVA. Un día previo al resultado de la PCR se había administrado suero con Traumeel, Ubichinon, Coenzyme, Hepar y Galium, expectoró durante la infusión y relató sentirse mejor luego de esto. Durante el procedimiento su saturación se mantiene en $89 \%$, se auscultó disminución del murmullo vesicular en base pulmonar izquierda. Al día siguiente con mejoría de la disnea, de la tos y sin fiebre. Ya con el resultado positivo para SARS-CoV-2 se formuló N-acetil cisteína $600 \mathrm{mg}$ cada 8 h, se le indicó continuar con Traumeel y spray nasal con Flamosin, Engystol.

Una semana después se encontraba sin disnea, sin tos, sin nuevos picos febriles, mejoría de la fatiga. Médico de su EPS le recomienda iniciar amoxicilina/ácido clavulánico basado en resultado de LDH la cual reportó valor de 278, PCR 27 y linfocitosis (5000), con Rx de tórax que evidenció atelectasia izquierda e infiltrados intersticiales bilaterales, sin embargo el paciente no inició tratamiento antibiótico pues se siente bien. En su lugar, ya que además sus saturaciones ya se encontraban superiores a 94\%, a la auscultación ya había normalidad y que el paciente se siente bien; se optó por nueva sueroterapia con Flamosin, Traumeel, Galium, Coenzyme y Ubichinon, se le indicó continuar con N-acetil cisteína vía oral y spray nasal con Flamosin y Engystol.

El paciente presentó excelente evolución durante el COVID y posterior a éste a pesar de que los paraclínicos y la rx de tórax evidencian gravedad. Un mes luego del la infección presentó 2 picos febriles de resolución y respuesta rápida ante la sueroterapia.

Por otro lado, en su seguimiento posterior al COVID y como parte de su seguimiento oncológico, se realizó seguimiento ecográfico de las masas tumorales y se evidencia importante disminución del tamaño de masa hepática: TAC de abdomen contrastado del 30.12.21 reportaba hígado severamente aumentado de tamaño por la presencia de múltiples lesiones metastásicas, la lesión de mayor tamaño en el segmento VIII que alcanza 12x9 cm. Líquido laminar subcapsular hepático.

En contraste, eco de abdomen del 03.06.21: Hígado con múltiples metástasis, la lesión de mayor tamaño de $43 \times 22 \mathrm{~mm}$ en segmento VIII, próstata con hipertrofia grado II, tamaño aumentado de bordes regulares, textura heterogénea, isoecogénico.

Al día de hoy ya no se palpa hepatomegalia, no hay dolor a la palpación abdominal, el estado nutricional del paciente es evidentemente mejor, es asintomático, ha recuperado su calidad de vida y sus labores.

\section{$\underline{\text { Diagnostics }}$}

\section{Perspective}

"A partir de comenzar el tratamiento, primero con sueros, los cuales me permiten volver a "vivir", he notado cambios positivos en mi cuerpo: como no tener el dolor que me aquejaba, volví a dormir normalmente, volví a hacer del cuerpo sin efuerzo y muy regulado todos los días, y volví a comer de “todo" sin sentir nauseas o deseos de vomitar los cuales eran producidos todos los días con solo percibir el olor a cualquier comida o al momento de verla servida en la mesa. también noté que mi parte derecha (donde está el hígado) se desinflamò y no volvi a palpar un " bulto " - el tumor, que allí se dejaba sentir al pasar la mano.

Tambien logré pasar el COVID- sin falta de aire, nunca me sentí ahogado y aunque el médico de la medicina prepagada me indicó por mi bajo nivel de saturación ir a urgencias, (indicación que no 
tomé en cuenta por no sentirme mal). Logré superarlo sin problemas, pues con la administración de sueros mis defensas estaban en un muy buen nivel aunque mi deterioro físico era muy fuerte para ese momento producido por estar y haber perdido casi 18 kilos en 20 días. Al ver mi RX de tórax pude comprobar el estado de deterioro por el COVID de mis pulmones, pero increíblemente por mi tratamiento nunca se sintieron así en mi día a día, incluso también mi EPS me indicó tomar un antibiótico muy fuerte, el cual decidí no ingerirlo y aún así y con exámenes de sangre cada 3 días mi cuerpo se recuperó completamente del COVID 19 y he notado posterior a él una importante mejoría en mi estado físico a pesar del cáncer aún cuando me habían dado 2 meses de vida"

\section{Francisco Bautista Rodríguez}

\section{$\underline{\text { Discussion }}$}

El caso descrito corresponde a una presentación clínica poco esperable de la neumonía por SARSCoV-2 ya que se trata de un paciente con varios factores pronósticos de gravedad ante la infección: neoplasia de órgano sólido con metástasis, elevación de LDH y PCR, adicionalmente con metástasis hepática de base y elevación importante en las pruebas de función hepática en el mes previo a la infección y con Rx de tórax que evidenció durante la infección neumonía por SARS-CoV-2 clasificada en escala de RALE con puntaje 4/8 (intermedio).

El examen físico yubican al paciente en la escala de predicción y gravedad NEWS2 (National Early Warning Score) con un puntaje de 7 y un riesgo elevado, lo cual es indicador de ingreso hospitalario urgente y, teniendo en cuenta sus antecedentes, para la escala PSI (Penumonia Severity Index) en clasificación IV del riesgo también con indicación de hospitalización pro el alto riesgo de mortalidad. Sin embargo, para la escala de amplio uso en atención primaria CRB-65, el paciente no presenta ningún puntaje, siendo entonces de bajo riesgo de mortalidad para esta escala ${ }^{[14]}$. Lo anterior supone una contrariedad y dificultad en la toma de decisiones de hospitalizar o no al paciente, sin embargo es claro que es un paciente que, mas que por sus signos vitales; por su condición previa al COVID 19 y por sus antecedentes, es de gran cuidado y requiere seguimiento permanente pues en cualquier momento puede presentarse cualquier tipo de desenlace no deseado. A pesar de todo esto, la clínica del paciente indicaba enfermedad leve y, a aunque sus médicos tratantes optaron por brindar tratamiento antibiótico y oxígeno, el paciente decidió continuar con tratamiento biorregulador el cual había iniciado un mes antes al evidenciar deterioro tras haber iniciado quimioterapia paliativa. $[3,5,7]$

En los pacientes oncológicos se ha evidenciado mayor correlación de la infección por SARS-CoV-2 con sobreinfección bacteriana, mayor requerimiento de ventilación mecánica y mayor mortalidad. Otros factores pueden ser claves en este contexto como evolución hacia la gravedad: el tipo ce cáncer (si es broncogénico), inmunosupresión, momento del diagnóstico. ${ }^{[6,7,8]}$

El tiempo promedio de detección de la neumonía es de 8 días a partir del inicio de los síntomas. En este caso, se detecta al día 13 con diagnóstico radiológico ya en fase de resolución pero con elevación aún importante de los reactantes. Adicionalmente, llama la atención que, a pesar de tener un puntaje moderado en la escala de RALE el paciente presenta síntomas leves y se ha llegado a detectar que hasta un $9 \%$ de los pacientes que cursan con diagnóstico radiológico de neumonía por SARS-CoV-2 es asintomático aunque mientras más extenso es el compromiso pulmonar, mayor es el riesgo de falla ventilatoria $[3,5,7]$.

En el caso expuesto, el paciente comenzó a recibir un enfoque biorregulatorio de su caso en el que, para recuperar su estado de salud postquimioterapia, le fueron administrados Traumeel, Galium, Sabal, Coenzyme y Ubichinon; todos enfocados a potenciar la capacidad autorreguladora del paciente para lograr su recuperación inicial ${ }^{[4,12]}$. En la medicina convencional la tendencia es a observar cada sistema de manera individual y los tratamientos son enfocados en el mismo sentido: el tratamiento de los síntomas. Sin embargo, su estado inicial era de gran inflamación y compromiso celular y se buscó reparar los sistemas afectados ${ }^{[4,10,12]}$, con lo cual se obtuvo excelente respuesta. Al cabo del primer mes de tratamiento, apareció la infección por COVID 19 en el mismo paciente, pero ahora con un terreno mucho mejor preparado para recibir al agente y con una neumonía viral 
que prácticamente pasó desapercibida a nivel clínico contra todo pronóstico y con una franca recuperación al cabo de 15 días de infección con el apoyo además de Engystol [10]

Posterior a la misma, el paciente continuó recibiendo tratamiento biorregulador sin quimioterapia (por decisión del paciente y su familia), pero con una impresionante mejoría constante, con disminución importante del tumor hepático, sin dolor y con una excelente calidad de vida, que además se evaluó mediante el cuestionario EuroQol5 (ver imagen anexa) en la cual el paciente obtuvo una mejoría postratamiento biorregulador de un $79 \%{ }^{[15]}$

\section{Conclusion}

La MBrS es una herramienta valiosísima para hacer un abordaje integral de cada paciente y lograr prevención de una evolución tórpida ante algunas enfermedades transmisibles, así como una recuperación global de enfermedades crónicas.

Es importante continuar investigando en este campo para darle el lugar que merece en la educación médica y en la práctica clínica.

\section{Acknowledgements}

A mis pacientes y sus familias, que me retan a diario.

A mi novio, por su motivación constante.

A mi amiga, María Isabel Palacio Montoya por su amable y enriquecedora asesoría en los aspectos de radiología de este caso.

\section{References}

1. Andrés O., B. and David Ladrón, D., 2013. Imágenes en oncología: generalidades y aplicaciones. Revista Médica Clínica Las Condes, [online] 24(4), pp.571-577. Available at: $<$ https://www.elsevier.es/es-revista-revista-medica-clinica-las-condes-202-articulo-imagenesoncologia-generalidades-aplicaciones-S0716864013701974> [Accessed 26 June 2021].

2. Coronaviruscolombia.gov.co. 2021. [online] Available at: $<$ https://coronaviruscolombia.gov.co/Covid19/index.html $>$ [Accessed 30 June 2021].

3. Castro, A., Antonio, T., Martínez, E., Gallardo, M., Gascón, M. and Pinos, D., 2021. Utilidad de la radiografía de tórax para evaluar el pronóstico de pacientes con COVID-19. Radiología, [online] Available at:

$<$ https://www.sciencedirect.com/science/article/pii/S0033833821001065> [Accessed 27 June 2021].

4. Goldman, A., Burmeister, Y., Cesnulevicius, K., Herbert, M., Kane, M., Lescheid, D., McCaffrey, T., Schultz, M., Seilheimer, B., Smit, A., St. Laurent, G. and Berman, B., 2015. Bioregulatory systems medicine: an innovative approach to integrating the science of molecular networks, inflammation, and systems biology with the patient's autoregulatory capacity?. Frontiers in Physiology, [online] 6. Available at: $<$ https://www.ncbi.nlm.nih.gov/pmc/articles/PMC4541032/pdf/fphys-06-00225.pdf> [Accessed 28 June 2021].

5. 2012. Haciendo visible el cáncer. 1st ed. [ebook] Viena, Austria: Sociedad Europea de Radiología, p.54. Available at: <https://www.internationaldayofradiology.com/app/uploads/2017/09/IDOR_2012_OncologyImaging_Spanish.pdf> [Accessed 28 June 2021].

6. Rojas, J., Wiesner, C., Gómez, J., Cuervo, S., Noviembre 2020. Reporte de caso: Presentación clínica e importancia de coinfecciones durante pandemia por COVID-19 en pacientes con neoplasias malignas. Revista Colombiana de Cancerología, [online] 24, pp.75-81. Available at: $<$ https://www.revistacancercol.org/index.php/cancer/article/view/709/529> [Accessed 24 June 2021].

7. Lee, H., Yoon, S., Lee, J., Park, T., Kim, D., Chung, H. and Heo, E., 2021. Clinical implication and risk factor of pneumonia development in mild coronavirus disease 2019 
patients. The Korean Journal of Internal Medicine, [online] 36(1), pp.1-10. Available at: $<$ https://www.ncbi.nlm.nih.gov/pmc/articles/PMC7820649/> [Accessed 29 June 2021].

8. Martínez Chamorro, E., Díez Tascón, A., Ibáñez Sanz, L., Ossaba Vélez, S. and Borruel Nacenta, S., 2021. Diagnóstico radiológico del paciente con COVID-19. Radiología, [online] 63(1), pp.56-73. Available at:

$<$ https://reader.elsevier.com/reader/sd/pii/S003383382030165X? token=DAC5E0F06332B637A59069C1223FE1FB70086493ADCB86D9A4A82F0A65DCACE98B147109F8A2F28EA6F12696C east-1\&originCreation=20210628152206> [Accessed 24 June 2021].

9. Milani, L., 2007. INFLAMMATION AND PHYSIOLOGICAL REGULATING MEDICINE. Fisiological regulating medicine, 1(1), pp.19-24

10. Wronski, S., Dannenmaier, J., Schild, S., Macke, O., Müller, L., Burmeister, Y., Seilheimer, B. and Müller, M., 2018. Engystol reduces onset of experimental respiratory syncytial virusinduced respiratory inflammation in mice by modulating macrophage phagocytic capacity. PLOS ONE, [online] 13(4), p.e0195822. Available at: $<$ https://www.ncbi.nlm.nih.gov/pmc/articles/PMC5909611/> [Accessed 28 June 2021].

11. Zhao, W., Zhong, Z., Xie, X., Yu, Q. and Liu, J., 2020. Relation Between Chest CT Findings and Clinical Conditions of Coronavirus Disease (COVID-19) Pneumonia: A Multicenter Study. American Journal of Roentgenology, [online] 214(5), pp.1072-1077. Available at: $<$ https://www.ajronline.org/doi/10.2214/AJR.20.22976> [Accessed 28 June 2021].

12. Martynchuk, A. and Popovych, S., 2016. Traumeel S - Bioregulatory Approach in Trauma and Inflammation. TRAUMA, [online] 17(2), p.13. Available at:

$<$ http://trauma.zaslavsky.com.ua/article/view/74627> [Accessed 28 June 2021].

13. Palacio Montoya, M., 2021. Residente de 3er año de Radiología Universidad CES

14. Spronhle, C., 2021. Evaluacion de la Gravedad de la Neumonia Adquirida en la Comunidad (NAC). [online] Medicinafamiliar.uc.cl. Available at: $<$ http://medicinafamiliar.uc.cl/html/articulos/162.html $>$ [Accessed 29 September 2021].

15. Herdman, M., Badia, X. and Berra, S., 2001. El EuroQol-5D: una alternativa sencilla para la medición de la calidad de vida relacionada con la salud en atención primaria. Atención Primaria, [online] 28(6), pp.425-429. Available at: $<\mathrm{https}$ ://www.elsevier.es/es-revista-atencion-primaria-27-articulo-el-euroqol-5d-unaalternativa-sencilla-13020211> [Accessed 13 October 2021].

\section{Attachments}

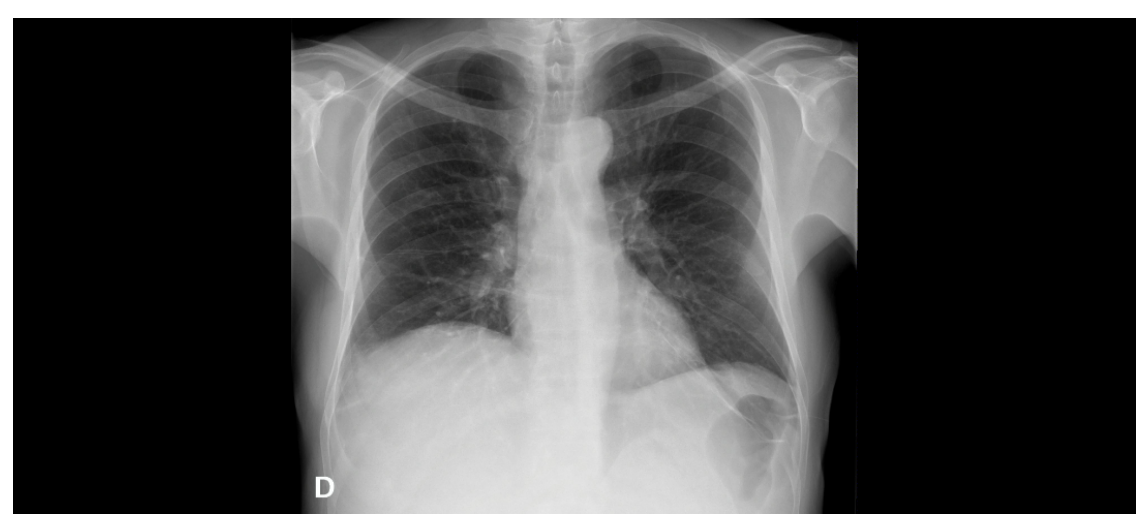

Rx de tórax del 07.01.21, un mes antes de la infección por SARS-CoV-2 


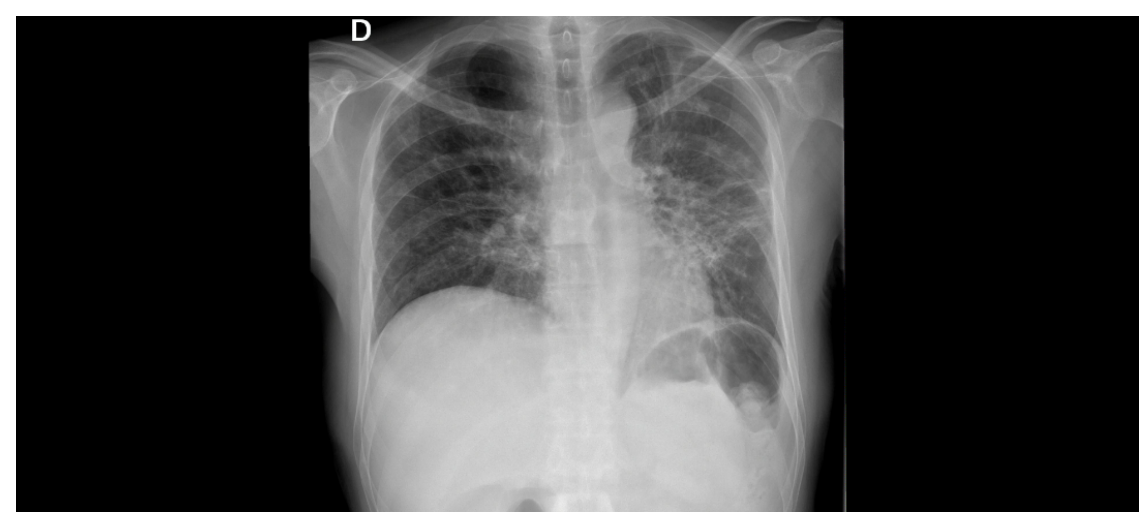

Radiografia el 19.02.21 (dia 10 desde el inicio de la infección por COVID 19), en la cual se observa

compromiso en hemitórax izquierdo, con patrón difuso reticular, opacidades periféricas en el mismo, asociado a atelectasias en ambos lóbulos y bronquiectasias izquierdas. Cambios compatibles con fase reparativa de la neumonia por SARS-CoV-2 [13].

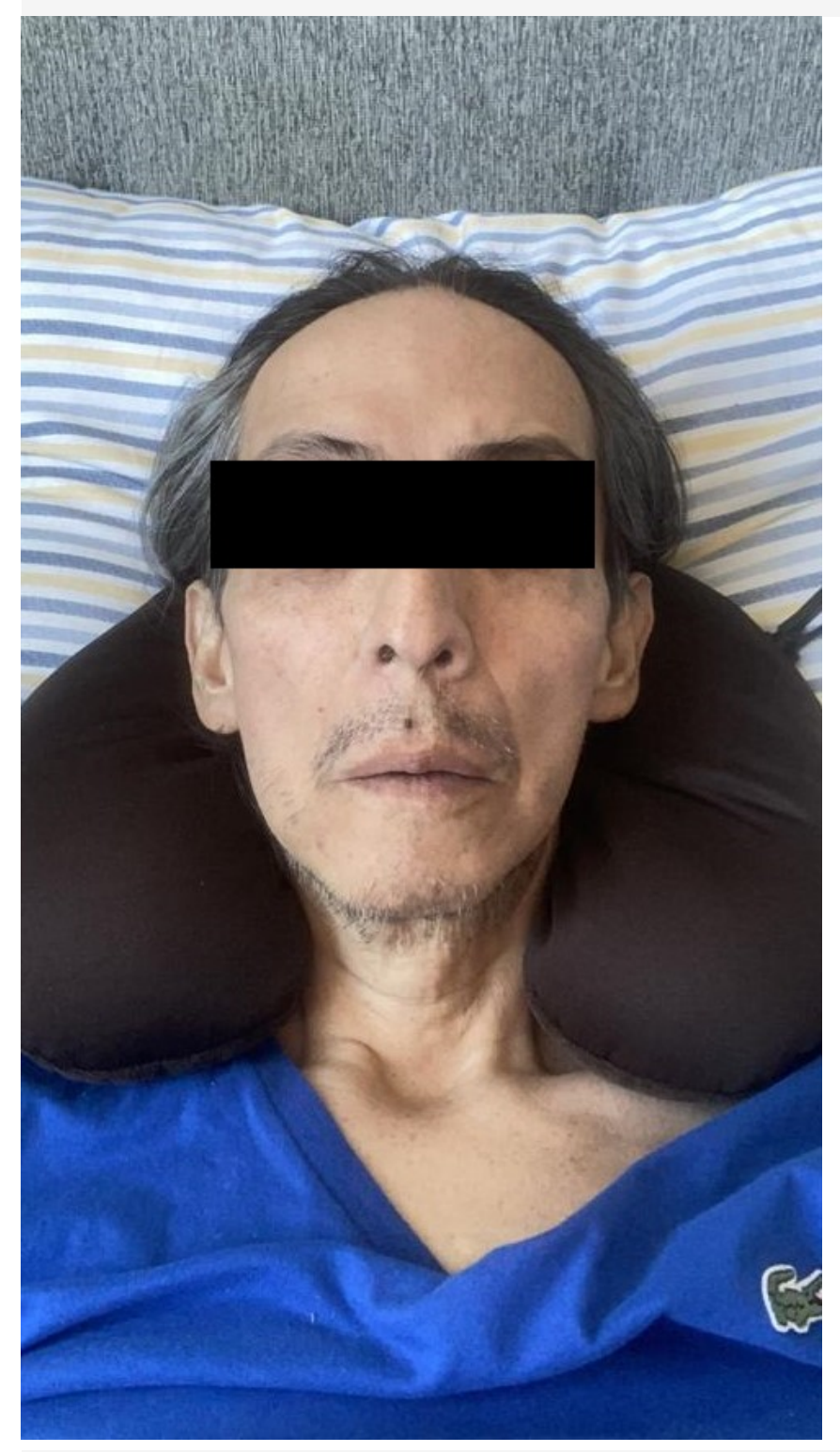

Imagen del paciente 20 días posteriores a la quimioterapia. En esta fase se comenzó tratamiento biorregulador, 1 mes antes de la infección por SARS-CoV-2 


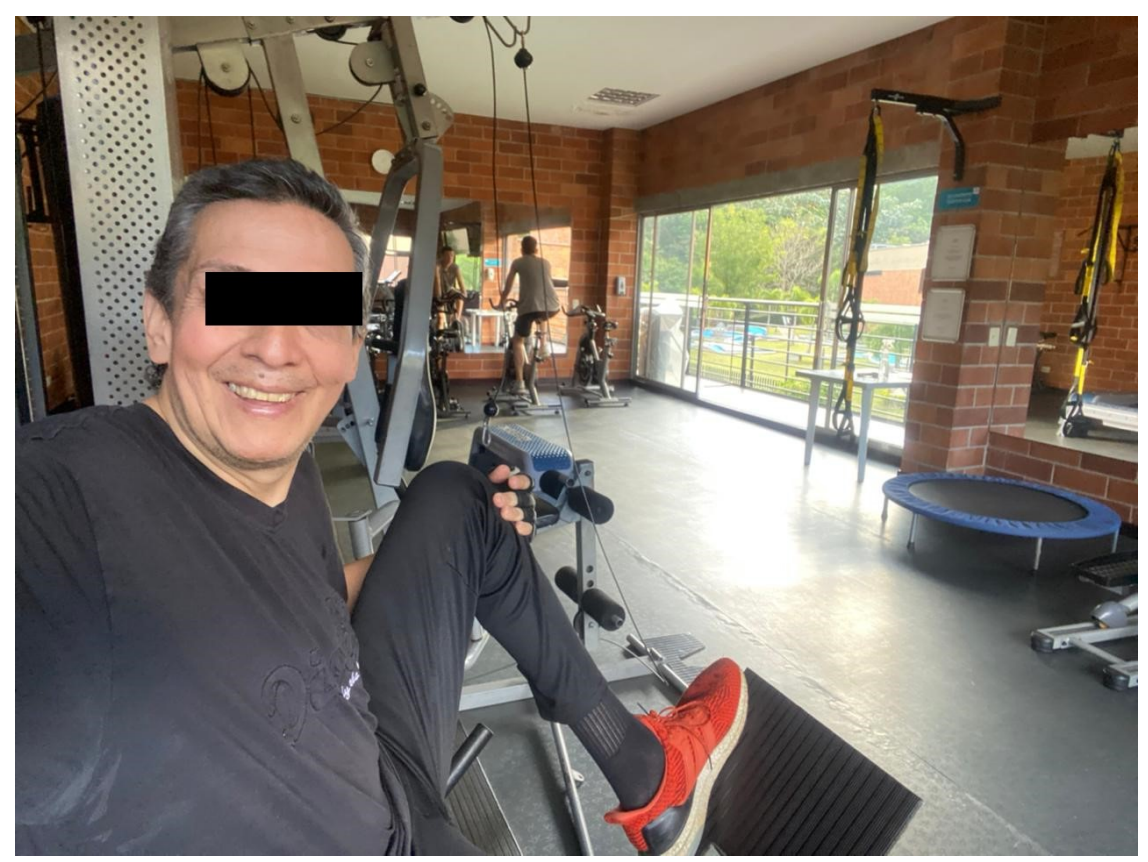

Paciente 5 meses después de haber iniciado tratamiento biorregulador y 4 meses después de la infección por COVID 19 


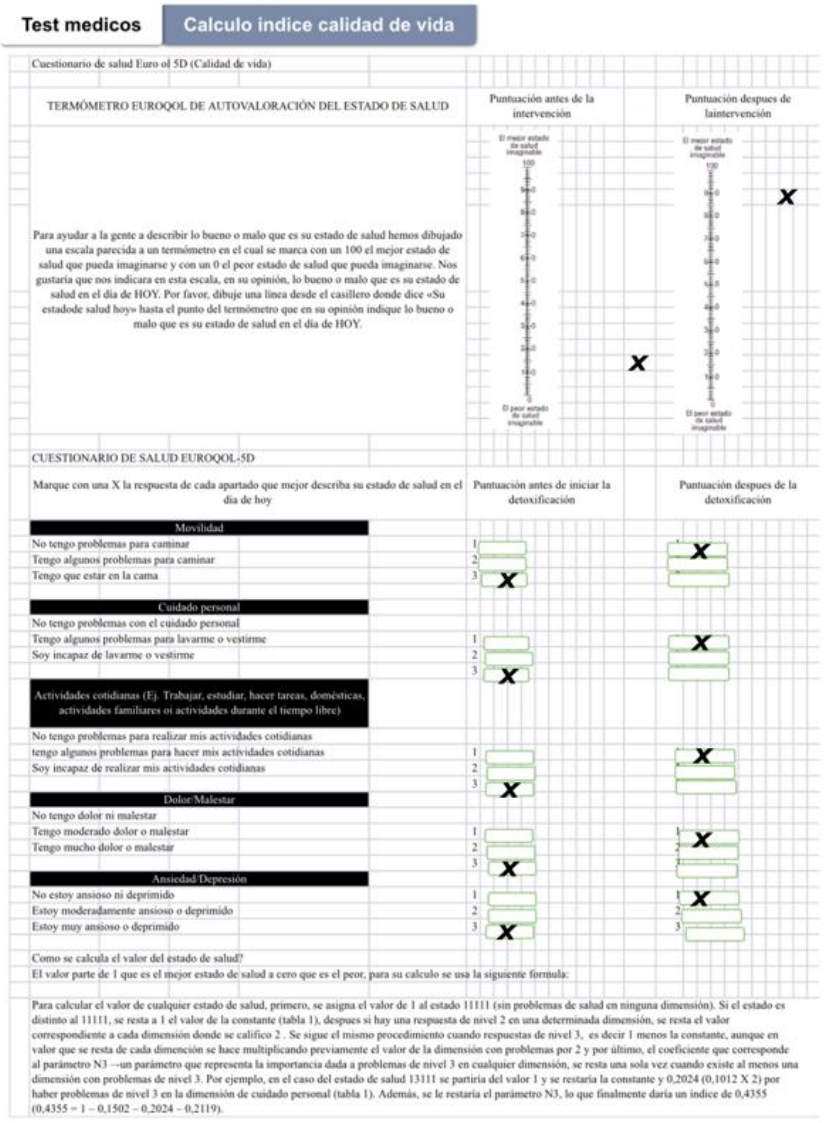

Cuestionario EuroQol5 - Calidad de Vida. En el termómetro general de calidad de vida este al final del tratamiento tuvo una mejoría de 7 puntos. Adicionalmente, la mejoría se vio en los 5 componente de calidad de vida pasando de un estado negativo de calidad de vida a un estado positivo del $79 \%$ 